\title{
Physicochemical, Photocatalytic, Antibacterial, and Antioxidant Screening of Bergenia Ciliata Mediated Nickel Oxide Nanoparticles
}

\author{
Fazal Ur Rehman ${ }^{1}$, Rashid Mahmood ${ }^{1}$, Manel Ben Ali ${ }^{2}$, Amor Hedfi $^{2}{ }^{\circledR}$, , Amine Mezni ${ }^{3}$, Sirajul Haq ${ }^{1, *}$, \\ Salah Ud Din ${ }^{1}$ and Rimsha Ehsan ${ }^{1}$ \\ 1 Department of Chemistry, University of Azad Jammu and Kashmir, Muzffarabad 13100, Pakistan; \\ fazal.rehman@ajku.edu.pk (F.U.R.); rashid.mehmood@ajku.edu.pk (R.M.); \\ salah.mahsud@ajku.edu.pk (S.U.D.); rimsha.ehsan.mphil@ajku.edu.pk (R.E.) \\ 2 Department of Biology, College of Sciences, Taif University, P.O. Box 11099, Taif 21944, Saudi Arabia; \\ mjbinali@tu.edu.sa (M.B.A.); o.zaied@tu.edu.sa (A.H.) \\ 3 Department of Chemistry, College of Science, Taif University, P.O. Box 11099, Taif 21944, Saudi Arabia; \\ a.rachid@tu.edu.sa \\ * Correspondence: siraj.ulhaq@ajku.edu.pk
}

check for

updates

Citation: Rehman, F.U.; Mahmood,

R.; Ali, M.B.; Hedfi, A.; Mezni, A.;

Haq, S.; Din, S.U.; Ehsan, R.

Physicochemical, Photocatalytic,

Antibacterial, and Antioxidant

Screening of Bergenia Ciliata

Mediated Nickel Oxide Nanoparticles.

Crystals 2021, 11, 1137. https://

doi.org/10.3390/cryst11091137

Academic Editor: Marilena Carbone

Received: 8 August 2021

Accepted: 15 September 2021

Published: 18 September 2021

Publisher's Note: MDPI stays neutra with regard to jurisdictional claims in published maps and institutional affiliations.

Copyright: (c) 2021 by the authors. Licensee MDPI, Basel, Switzerland. This article is an open access article distributed under the terms and conditions of the Creative Commons Attribution (CC BY) license (https:// creativecommons.org/licenses/by/ $4.0 /)$.

\begin{abstract}
This study was planned to synthesize a multifunctional nanomaterial that can effectively encounter the organic pollutants, multidrug-resistant bacteria and reactive free radicals. The Bergenia ciliate (B. ciliate) leaves extract was used as a reducing and capping agent for the synthesis of nickel oxide nanoparticles ( $\mathrm{NiO} \mathrm{NP}$ ). The physicochemical properties were studied through X-ray diffractometre (XRD), energy dispersive $X$-ray (EDX), scanning electron microscopy (SEM), transmission electron microscopy (TEM), UV-visible and Fourier transform infrared (FTIR) spectroscopies. The highly crystalline monoclinic NiO NPs were synthesized with crystallite size of $27.45 \mathrm{~nm}$. The average particle size derived from TEM micrograph was $49.35 \mathrm{~nm}$ whereas the calculated band gap for NiO NPs was $3.78 \mathrm{eV}$. The photocatalytic study shows that $92.17 \%$ of the rhodamine $6 \mathrm{G}$ (Rh-6G) was efficiently degraded in the presence of NiO NPs. The agar well diffusion method was applied to examine the antibacterial activity of NiO NPs and the activity was found higher against Gram-negative bacteria (GNB) as compared to Gram-positive bacteria (GPB). The ABTS free radical scavenging activity was also performed, however, the activity was found less than the standard.
\end{abstract}

Keywords: green synthesis; nickel oxide; microscopy; monoclinic; polyhedral

\section{Introduction}

The breakneck engineering achievements and the urbanization with increasing population growth have provoked the massive extrication of the toxic contaminants in the air and water, thus polluting these precious resources. Amongst all the sources of these contaminants, the most distinct are the azo dyes that are hazardous and non-biodegradable produced by the commercial manufacturers [1]. Damping of these dyes in the water and surroundings by the industries is lethal to human health and safety and is a cause of environmental contamination. Moreover, these dyes are damaging the aquatic environment by affecting the watery plants and interrupting the photosynthesis in aquatic flora. In view of all these consequences there is an urgent need to convert these hazardous materials to non-hazardous materials [1,2]. Various methods employed for the treatment of these toxic substances include coagulation, active sludge, reverse osmosis and electrochemical oxidation, but the organic compounds seemed to be stable against chemicals and the treatments and were still persistent in the water even after these treatments [3]. Recently, photocatalytic degradation has been suggested as an environment friendly and inexpensive method to eradicate the organic materials and pollutants from the waste water on manipulating the semiconductor metal oxides like $\mathrm{TiO}_{2}, \mathrm{ZnO}, \mathrm{CuO}$ and $\mathrm{NiO}$ [4].

Moreover the introduction of various herbicides, fungicides, plasticizers and the insecticides through domestic, agricultural, medical and industrial activities is causing a 
damaging effect to our environment by the production of various pathogens and disease causing organisms [5]. There is an urgent need to develop some method to treat the bacterial diseases as the emerging pathogens have developed resistance against most of the antibacterial and antimicrobial agents. In the recent days, the nano-sized drug carriers and the antibacterial agents have proved to be efficient against most of the pathogens and have shown a remarkable performance in the treatment of infectious diseases [6]. Currently, the NiO NPs have much fascinated the researchers for their p-type conductivity and a direct band gap of 3.6-4.0 eV along with the distinctive applications. These NPs have been extensively used for anti-microbial activity, catalysis, photocatalysis, in gas sensors, electrochemical films, smart windows and photo-electronic devices [7-11]. The non-toxicity, easy and cheap availability and photo-stability of NiO NPs make them suitable photocatalysts for the mineralization of various organic pollutants. Many researchers have manipulated NiO NPs for antibacterial activities and for the degradation of dyes [12-15]. The antibacterial activity of the NPs is dependent on the size, stability and concentration and they provide a greater retention time during the antibacterial activity while interacting with the bacteria [16]. The B. ciliata plant grows between 7000 and 10,000 feet in the temperate Himalayas, from Kashmir to Bhutan. Bergenin, Tannic acid, Gallic acid, Stigmesterol, -Sitosterol, Catechin, (+)-Afzelechin, 1,8-cineole, Isovalaric acid, (+)-(6S)-parasorbic acid, Arbutin, -eudesmol, 3-methyl-2-buten-1-ol, (Z)-asarone, Terpin are the phytochemicals identified in $B$. ciliate and act as bioreductants and capping agents in the production and stabilization of metals and metal oxide nanoparticles. B. ciliate is a medicinal plant locally used to cure a variety of illnesses (including diarrhoea and vomiting), as well as fever, cough, and lung infections [17].

Different applications of NiO NPs were reported after they were synthesized in different ways. However, they were not used for many applications after the same synthesis. Moreover, the use of NiO NPs as photocatalysts against Rh-6G, an antibacterial agent against pathogenic bacteria, and ABTS-free radical scavenging agents has yet to be reported. Here in this project, the NiO NPs have been synthesized by using a time-saving, economical, and environmentally friendly plant-mediated method, where B. ciliata leaf extract was used as a reducing and capping agent and nickel nitrate was used as the source of nickel. The physicochemical properties were investigated via different techniques such as XRD, SEM, TEM, EDX, FTIR and UV-Visible spectroscopy. The as-fabricated NPs were manipulated for photocatalytic, antibacterial and antioxidant studies.

\section{Materials and Methods}

\subsection{Chemical Used}

The analytical grade chemicals obtained from Sigma-Aldrich were manipulated in the current project. Nickel nitrate, ethanol, rhodamine 6G, and Agar nutrients were used in this project. All the required solutions were prepared in distilled water.

\subsection{Preparation of Plant Extract}

The green leaves of $B$. ciliate were collected in the month of April from Neelum valley $\left(34.5985^{\circ} \mathrm{N}, 73.9073^{\circ} \mathrm{E}\right)$, Azad Kashmir, Pakistan. For the preparation of the aqueous extract, $20 \mathrm{~g}$ of $\mathrm{B}$. ciliate leaves were boiled in $200 \mathrm{~mL}$ of distilled water at $70{ }^{\circ} \mathrm{C}$. After $15 \mathrm{~min}$, the aqueous extract was filtered through Whatmann No.1 filter paper to get the clear plant extract. The aqueous leaves extract was used as a reducing agent for the synthesis of nanomaterials.

\subsection{Green Synthesis of $\mathrm{NiO} N P s$}

For the typical synthesis of NiO NPs, $5 \mathrm{mM}$ stock solution was prepared in $1000 \mathrm{~mL}$ by dissolving $1.45 \mathrm{~g}$ of $\mathrm{Ni}\left(\mathrm{NO}_{2}\right)_{2} \cdot 6 \mathrm{H}_{2} \mathrm{O}$, and $80 \mathrm{~mL}$ of this solution was mixed with $20 \mathrm{~mL}$ $\mathrm{B}$ ciliate. The mixture was heated and stirred for $15 \mathrm{~min}$ and then the $\mathrm{pH}$ was adjusted at 10 by the dropwise addition of $\mathrm{NaOH}$ solution. The heating and stirring was continued for $45 \mathrm{~min}$ further and the greenish gel formed was aged for $24 \mathrm{~h}$ and was then washed 
with deionized water thrice. The solid product was oven dried at $150{ }^{\circ} \mathrm{C}$ and stored in a polyethylene bottle.

\subsection{Physicochemical Characterization}

The crystalline nature of the synthesized NiO NPs was studied by XRD model Philips $X^{\prime}$ Pert and the crystallite size was estimated using Debye-Scherrer equation. The microstructure and surface topology was studied with SEM Model JEOL JSM-5600LV, Tokyo, Japan and Hitachi HT7800 transmittance electron microscope (TEM) Cleveland, TN, USA. Energy-dispersive X-ray (EDX) analysis was carried out by using EDX model INCA 200, Oxford Instruments, Oxfordshire, UK coupled with SEM to confirm the composition of the sample. The UV-Visible spectroscopic analysis was carried out to study the optical properties using Shimadzu (UV-800) provided by Thermo Fisher Scientific Waltham, MA, USA whereas the surface functional moieties was investigated through FTIR model Nicolet 560, Thermo Fisher Scientific Waltham, MA, USA was operated in the range between 4000 and $400 \mathrm{~cm}^{-1}$ [18].

The photocatalytic efficacy of NiO NPs was evaluated during the degradation of Rh-6G in the presence solar light in month June between 11 a.m. to 3 p.m. For the typical photochemical reaction, $25 \mathrm{mg}$ of the catalyst was added to the reaction vessel containing $70 \mathrm{~mL} \mathrm{Rh}-6 \mathrm{G}$ solution and was stirred in the dark for half hour. Afterward, the reaction mixture was irradiated under solar light and the UV analysis was carried out after a specific time interval (i.e., 5, 10, 20, 40, 60, 80, 100, 120, 140, 160 and $180 \mathrm{~min}$ ). The decrease in the absorbance maxima with the passage of time suggests the degradation of Rh-6G.

\subsection{Antibacterial Assay}

The antibacterial activity of the NiO NPs was examined against the GPB (S. aureus (ATCC \# 6538)) and GNB (E. coli (ATCC \# 15224)) using the Agar well diffusion method. The plates were prepared by mixing Agar nutrients in deionized water and solidified naturally at room temperature. The bacterial culture grown overnight was spread over the media and the wells were bored with a polystyrene tip. The stock suspension was prepared by ultrasonic dispersion of $5,15,25$ and $50 \mathrm{mg}$ of NiO NPs in $5 \mathrm{~mL}$ deionized water and $100 \mu \mathrm{L}$ was added into each well. The plate were then incubated at $37^{\circ} \mathrm{C}$, and after $24 \mathrm{~h}$, the zone of inhibition was measured in millimetres $(\mathrm{mm})$ as the activity of NiO NPs.

\subsection{Antioxidant Assay}

Firstly, the ABTS ${ }^{\bullet+}$ was generated by nixing $5 \mathrm{mM}$ potassium persulphate and $14 \mathrm{mM}$ of ABTS and kept in dark for $16 \mathrm{~h}$ and the absorbance of the solution was checked at $734 \mathrm{~nm}$. The stock suspensions of NiO NPs was prepared by ultrasonic dispersion of 5, 25, 50, 75, 100 and $200 \mu \mathrm{g}$ in $1 \mathrm{~mL}$ for $30 \mathrm{~min}$ at room temperature. The $0.2 \mathrm{~mL}$ of NiO NPs suspension and $0.15 \mathrm{~mL}$ of $\mathrm{ABTS}^{\bullet+}$ solution was mixed and aged for $30 \mathrm{~min}$ and then subjected to UV analysis to check the absorbance at $734 \mathrm{~nm}$. The percentage of ABTS radical inhibition activity was determined by using Equation (1); where Ai is the absorbance of the sample and Ao is the absorbance of the control.

$$
\% \mathrm{RSA}=\left[\frac{\mathrm{A}_{\mathrm{o}}+\mathrm{A}_{\mathrm{i}}}{\mathrm{A}_{\mathrm{o}}}\right] \times 100
$$

\section{Results and Discussion}

\subsection{Physicochemical Study}

3.1.1. XRD Analysis

The X-ray diffractogram of NiO NPs shown in Figure 1 possesses the diffraction peaks at two theta positions, $37.20,43.31,63.86,75.36$ and 79.43 , corresponding to miller indices of plane $(001),(-111),(-311),(-221)$ and $(-402)$. In all these bands the hkl values exactly matched the data listed in JCPDS card 01-072-1464, confirming the monoclinic geometry of the crystals, with space of $\mathrm{C} 2 / \mathrm{m}$. The length of a coordinate is $5.1150 \AA$ whereas those $\mathrm{b}$ and c coordinates are equal to $2.9580 \AA$. The alpha and gamma are equal $\left(90^{\circ}\right)$ although 
beta is equal to $125.19^{\circ}$. The XRD data briefly explain the $\mathrm{NiO}$ crystal quality, where the intense diffraction bands with narrow FWHM suggest the formation of highly crystalline material. Furthermore, that all the bands appeared is due to $\mathrm{NiO}$, so no other peak seen in the diffractogram suggests the formation of a highly pure sample. The average crystallite size was found to be $27.45 \mathrm{~nm}$, whereas $1.34 \%$ lattice strain was found in the crystal.

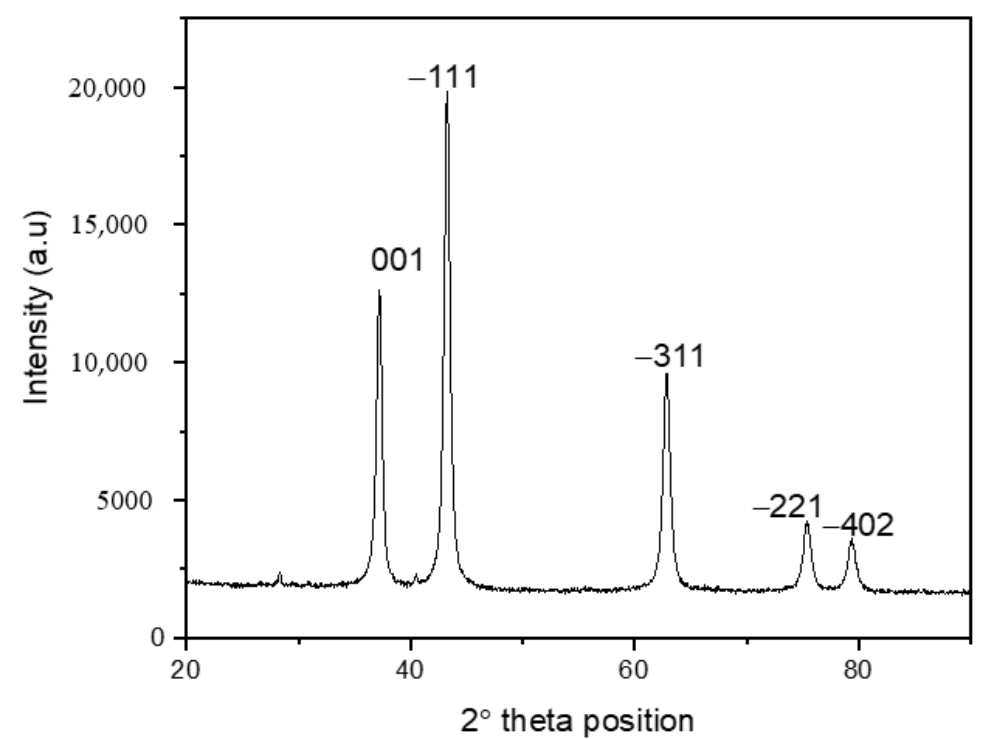

Figure 1. XRD pattern of NiO NPs.

\subsubsection{Microstructure Analysis}

The SEM micrograph shown in Figure 2a shows that well defined shaped particles are formed, which exhibit clear boundaries. The majority of the particles exhibited are squareshaped while other polyhedral particles are also present. The particle distributions are not smooth and several cavities are seen in the micrograph. The surface morphology of the biogenically fabricated NiO NPs was investigated through a scanning electron microscope. It is seen from the figure that the particles are highly agglomerated due to high energy and high surface area to volume ratio. The TEM analysis (Figure $2 b$ ) was carried out in the study the morphology of the synthesized NiO NPs, where most of the particles seem to be tetrahedral. Beside these, few pseudo-spherical and polyhedral particles are also observed. The particles are evenly distributed and possess well defined boundaries, whereas few particles are closely packed together. The particle sizes estimated from the TEM micrograph using ImageJ software range from 23.89 to 62.50 with an average size of $49.35 \mathrm{~nm}$.

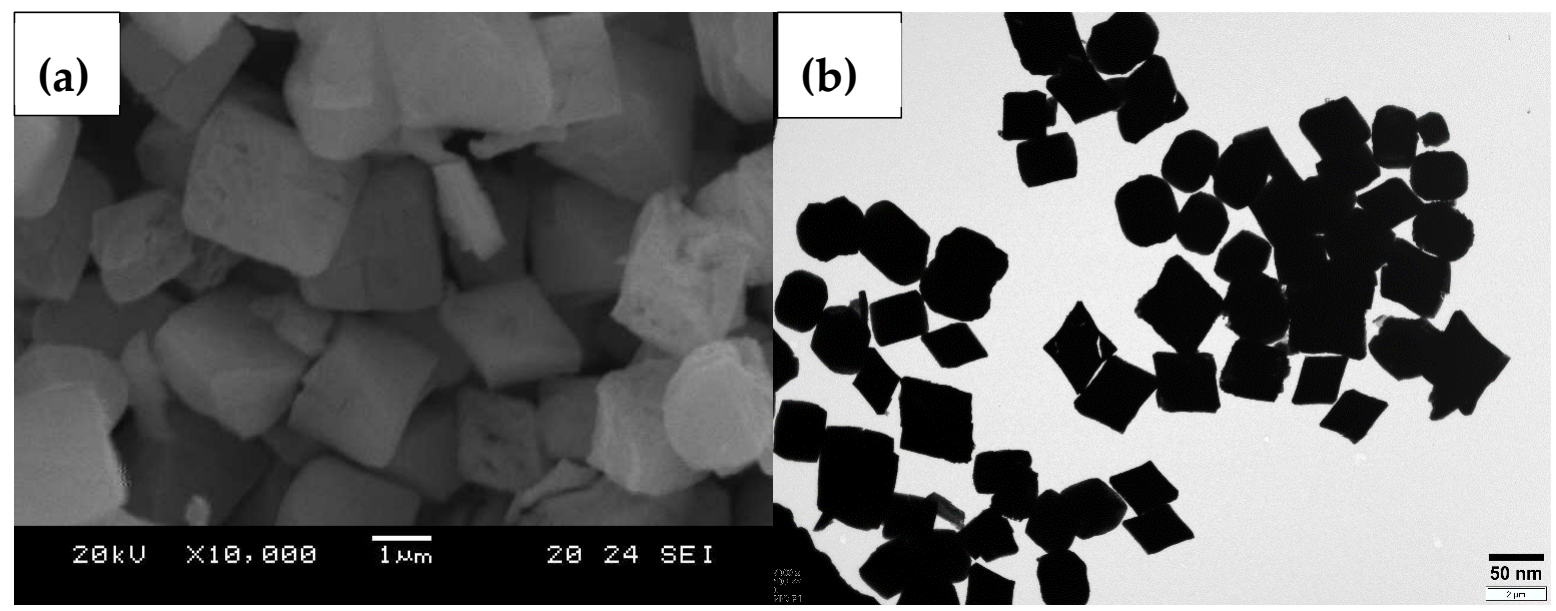

Figure 2. SEM (a) and TEM (b) micrographs of NiO NPs. 


\subsubsection{UV-Visible and EDX Analysis}

The literature survey shows that the UV-Visible absorbance for NiO NPs was reported at 284, 310 and $381 \mathrm{~nm}$, however, in the present study the absorbance edge was located at $327.62 \mathrm{~nm}$ (Figure 3), to which the synthesized NiO NPs showed photo-response in the UV region [10]. Several studies have been reported on $\mathrm{NiO}$ synthesized via both chemical and green methods, with absorbance in the range of $320-330 \mathrm{~nm}$, the shift between this is due to the confinement of electron-hole carrier and responsible for the optical transition of the valence electron to conduction band, which are used to calculate the band gap energy $[3,19]$. The band gap energy calculated on the basis of basis of absorbance edge was $3.78 \mathrm{eV}$, which was found to be similar to that reported previously [11]. The elemental composition and purity percentage of the NiO NPs was determined through the EDX analysis and the spectrum obtained confirms the presence of $\mathrm{Ni}$ and $\mathrm{O}$ as shown as inset in Figure 3. The weight percentages of $\mathrm{Ni}$ and $\mathrm{O}$ obtained were $87.72 \%$ and $10.94 \%$, respectively. The $0.93 \%$ $\mathrm{C}$ present in the sample is due to the use of carbon tape during analysis whereas the $0.41 \%$ Mn that was present in the sample is an impurity, which might be due to the use of plant leaves extract.

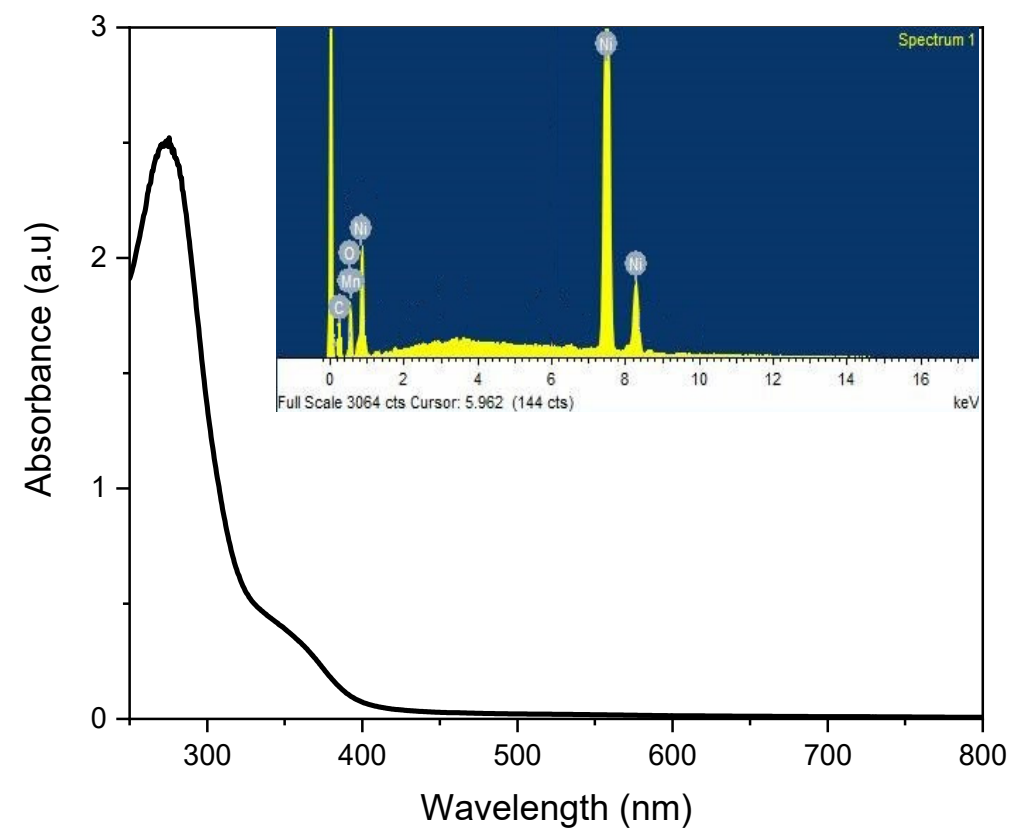

Figure 3. UV-visible spectrum (inset: EDX spectrum) of NiO NPs.

\subsubsection{FTIR Analysis}

The FTIR spectrum shown in Figure 4 exhibits the characteristic peaks for NiO NPs in the range of 1236 to $440 \mathrm{~cm}^{-1}$, whereas the other peaks related with water molecules and phytochemicals occurred in the sample due to the use of plant leaves extract. The peaks at 440.21 and $545.23 \mathrm{~cm}^{-1}$ are due to the wagging and bending vibration of terminal O-H and Ni-O groups, respectively [13]. The band at $1020.52,1110.80$ and $1236.38 \mathrm{~cm}^{-1}$ is because of $\mathrm{Ni}-\mathrm{O}$, terminal $\mathrm{Ni}-\mathrm{OH}$ and $\mathrm{O}-\mathrm{Ni}-\mathrm{O}$ stretching of the lattice structure, respectively [20]. The peaks at $1383.31 \mathrm{~cm}^{-1}$ are due to the nitro group, which is due to the use of nickel nitrate as a precursor to salt during synthesis [21]. The peaks at 1648.44 and $3450.06 \mathrm{~cm}^{-1}$ were due to the starching bending vibration of water molecules, respectively, whereas the peak at $3649.66 \mathrm{~cm}^{-1}$ is attributed to N-H moiety, which might be due to the utilization of plant leaves extract during synthesis [22]. 


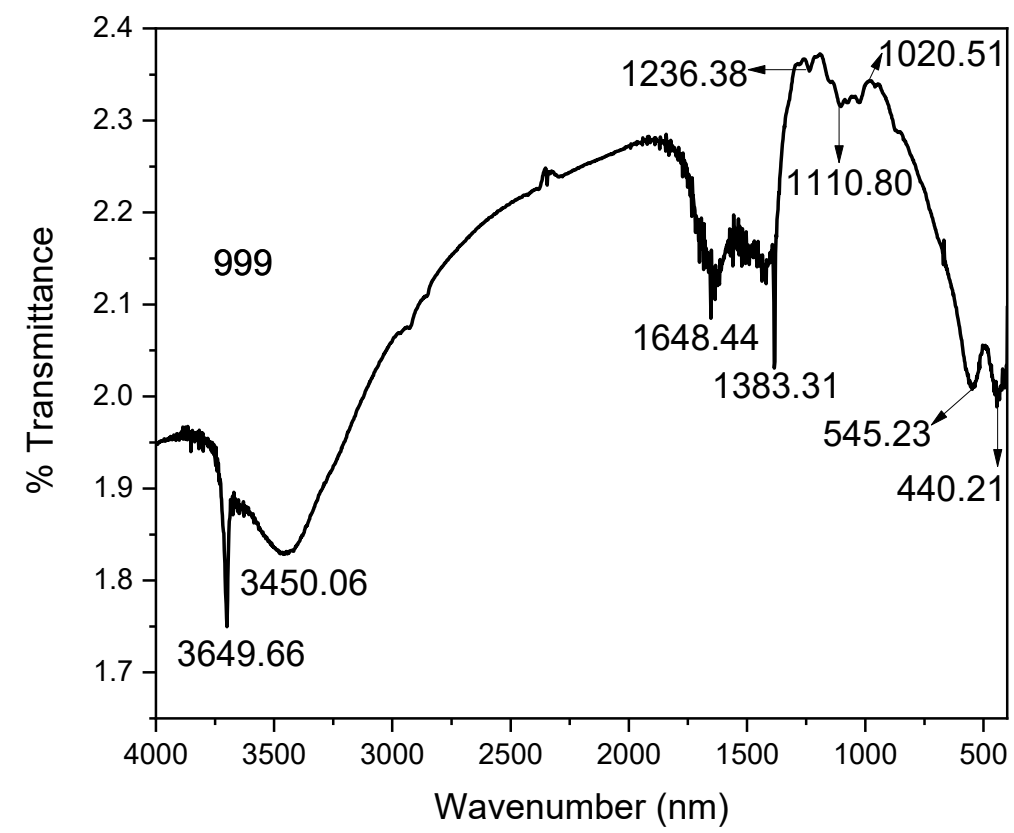

Figure 4. FTIR spectrum of NiO NPs.

\subsection{Photocatalytic Activity}

Figure 5 exhibits the photocatalytic degradation of the Rh-6G using plant-mediated $\mathrm{NiO}$ NPs. The NiO NPs were introduced to the solution at room temperature and were analysed under solar light at a wavelength of $526 \mathrm{~nm}$. The decrease in absorbance maxima at the same wavelength indicates the degradation of dye molecules under solar light irradiation as shown in Figure 5a. The photocatalytic efficiency of biogenically fabricated $\mathrm{NiO} N P s$ was analysed under the full light spectrum for the degradation of Rh-6G. The $60 \mathrm{~mL}$ of the stock solution was transferred to a reaction vessel and $10 \mathrm{mg}$ of the catalyst was introduced to the vessel. To establish the adsorption-desorption equilibrium, the solution was first stirred in the dark for almost $30 \mathrm{~min}$. Figure $5 \mathrm{~b}$ [23]. After stirring in the dark for $30 \mathrm{~min}$ the liquid samples were analysed spectrophotometrically after definite intervals of time $(5,10,20,40,60,80,100,120,140,160,180 \mathrm{~min})$ and bright colour faded with the passage of time. The decrease in absorbance maxima was noted at $526 \mathrm{~cm}^{-1}$ and other less intense peaks as a function of time interval as shown in Figure 5b, which shows that the degradation of Rh-6G was gradual with passage of time. The sharp increase in the degradation process was seen up to $20 \mathrm{~min}$, where a comparatively steady increase in the degradation was experienced above $20 \mathrm{~min}$. The slow increase in the degradation might be due to a minute dye adsorption on the catalyst surface, reducing the exposure of the catalyst to solar light. Equations (2) and (3) were used to calculate the percentage degradation and degradation rate constant of the photocatalytic reaction. The after 180 min percentage degradation of Rh-6G was found to be $92.17 \%$ with a degradation rate of $2.402 \times 10^{-2} / \min$ (Figure $5 \mathrm{c}, \mathrm{d}$ ) [24].

$$
\begin{gathered}
\% \text { Degradation }=\frac{C_{o} \times C_{i}}{C_{o}} \times 100 \\
\ln \left(\frac{C}{C_{o}}\right)=-k t
\end{gathered}
$$



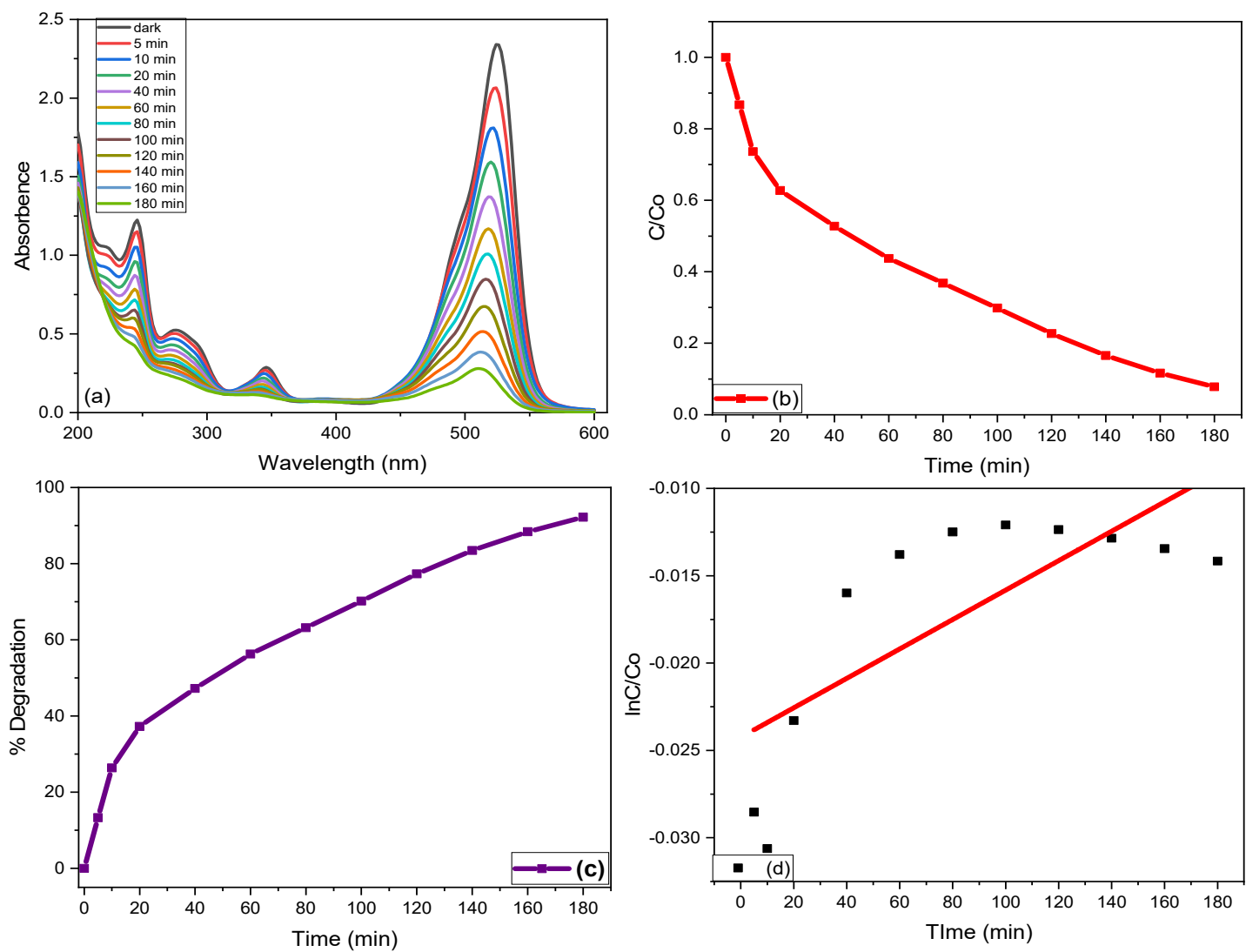

Figure 5. (a) Degradation profile; (b) $\mathrm{C} / \mathrm{C}_{\mathrm{o}}$ plot; (c) \% degradation; (d) Degradation rate constant of Rh-6G in the presence of NiO NPs.

\subsection{Antibacterial Activity}

The antibacterial efficacy of the NiO NPs was tested against E. coli (ATCC \# 15224) and S. aureus (ATCC \# 6538) and the inhibition zones were measured in millimetres (Table 1), which shows that the activity gradually increases with increasing concentration of $\mathrm{NiO}$ suspension in the wells (Figure 6a,b). The minimum inhibition concentration for E. coli and S. aureus under the experimental condition was $5 \mathrm{mg} / 5 \mathrm{~mL}$ and $25 \mathrm{mg} / 5 \mathrm{~mL}$ respectively. A similar finding was also reported previously, suggesting that larger numbers of NiO NPs in the suspension are able to produce more $\mathrm{Ni}^{2+}$ ions results into the extensive penetration inside the bacterial cell [25]. The antibacterial activity of NiO NPs at a higher concentration $(50 \mathrm{mg} / 5 \mathrm{~mL}$ ) was almost comparable with standard drugs. The activity results also depict that the inhibition zone was larger in the case of GNB as compared to GPB, which might be due to the difference in the cell wall composition and surface charges. The cell wall of GPB consists of multiple peptidoglycans layers, whereas the GNB has few peptidoglycans layers in the cell wall. The former provide more strength to GPB cell as compared to GNB cell and prevent/control the penetration of $\mathrm{Ni}^{2+}$ ions [26]. The $\mathrm{Ni}^{2+}$ ions not only accumulate on the surface but also penetrate the bacterial cell, disturbing the cytoplasmic activity. It has been suggested that the respiration process was greatly inhibited due to the interaction of $\mathrm{Ni}^{2+}$ with the thiol group of the proteins molecule, which eventually led to the death of bacteria [27]. This concept attributes NiO NPs toxicity to the solubility of $\mathrm{Ni}^{2+}$ in the media, which includes microorganisms. The disintegration phenomena is rather debatable, despite the fact that it has been adopted and accepted. However, it was assumed that the $\mathrm{Ni}^{2+}$ release mechanism is controlled by the physicochemical characteristics of the particles, which include porosity, concentration, particle size, and morphology and media chemistry like $\mathrm{pH}, \mathrm{UV}$ light, exposure duration and the presence of additional components. However, the impact of these factors is not well understood [28]. 
Table 1. Antibaterial activity of NiO NPs against E. coli and S. aureus at different concentration.

\begin{tabular}{|c|c|c|c|c|c|c|}
\hline \multirow{2}{*}{ Bacteria } & \multicolumn{6}{|c|}{ Zones of Inhibition Measured in Millimeter (mm) with Error of \pm 2} \\
\hline & $5 \mathrm{mg} / 5 \mathrm{~mL}$ & $15 \mathrm{mg} / 5 \mathrm{~mL}$ & $25 \mathrm{mg} / 5 \mathrm{~mL}$ & $50 \mathrm{mg} / 5 \mathrm{~mL}$ & PC & Solvent \\
\hline E. coli & 1.87 & 3.93 & 8.63 & 13.09 & 14.72 & 00 \\
\hline S. aureus & 00 & 00 & 4.01 & 10.29 & 12.37 & 00 \\
\hline
\end{tabular}

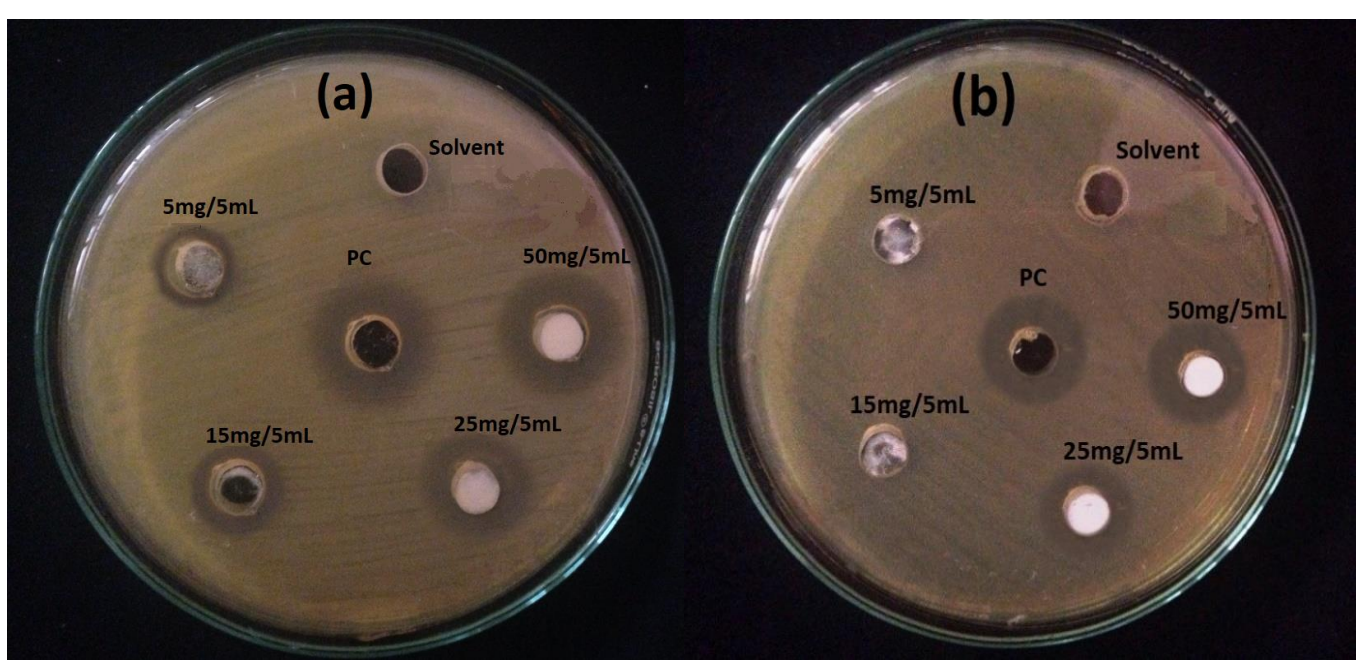

Figure 6. Pictographic illustration of antibacterial activity of NiO NPs against E. coli (a) and S. aureus (b).

\subsection{Antioxidant Activity}

The antioxidant activity of NiO NPs was screened against the ABTS ${ }^{\bullet+}$ in methanolic solution and the activity was compared with ascorbic acid used as control and results obtained was illustrated in Figure 7. The different concentration of NiO NPs and ascorbic acid was treated with a solution containing $\mathrm{ABTS}^{\bullet+}$ to determine the percentage radical scavenging activity [29]. It was observed that the antioxidant activity increased with increasing concentration of the both the samples, suggest that a larger number of antioxidants is required to neutralize the $\mathrm{ABTS}^{\bullet+}$ radical cation. The $\mathrm{IC}_{50}\left(\mu \mathrm{gmL}^{-1}\right)$ value is the concentration of antioxidant that can neutralize $50 \%$ of the $\mathrm{ABTS}^{\bullet+}$ radical cation. The calculated $\mathrm{IC}_{50}$ value for NiO NPs is $49.63 \mu \mathrm{gmL}^{-1}$ and that for ascorbic acid is $14.99 \mu \mathrm{gmL}^{-1}$, suggesting that the activity of NiO NPs was less than ascorbic acid.

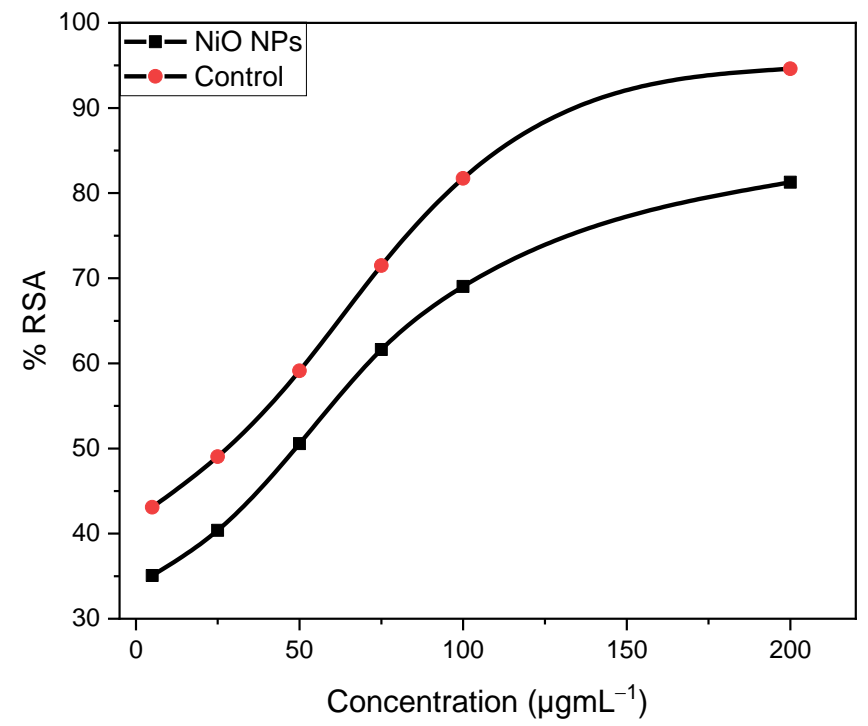

Figure 7. Percentage radical scavenging activity of NiO NPs and control (ascrobic acid). 


\section{Conclusions}

An eco-friendly and efficient process was followed for the synthesis of highly crystalline nano-sized NiO NPs, which exhibit enhanced photocatalytic, antibacterial and antioxidant potential. The examined physicochemical properties confirm the formation of extremely pure NiO NPs, where the majority of the particles exhibit tetrahedral geometry. The photocatalytic results suggest that Rh-6G was efficiently degraded in the presence of $\mathrm{NiO} N P$. The higher antibacterial activity against $E$. coli as compared to $S$. aureus might be due to the difference in the cellular structure. The photocatalytic, antibacterial and antioxidant activities suggest that the synthesized NiO NPs is a multifunction candidate and must be utilized in future for the purification of waste water, inhibition of bacterial growth and scavenging of free radicals. This study provides sensible results that prove that $\mathrm{NiO}$ NPs are a multifunctional material that can be obtained by a very simple method and can be utilized for other applications in future.

Author Contributions: Conceptualization, R.M. and S.H.; methodology, R.M. and S.H.; validation, R.M., S.H. and F.U.R.; formal analysis, F.U.R.; investigation, S.H. and F.U.R.; resources, R.M. and S.H.; data curation, S.H., A.H. and F.U.R.; writing-original draft preparation, S.H., R.E. and F.U.R.; writing-review and editing, R.M., M.B.A., A.M. and S.H.; visualization, S.U.D.; supervision, R.M. and S.H.; project administration, R.M. and S.H.; funding acquisition, M.B.A., A.M. and A.H. All authors have read and agreed to the published version of the manuscript.

Funding: This research received no external funding.

Data Availability Statement: Not applicable.

Acknowledgments: The authors are grateful to the Deanship of Scientific Research for funding this article by Taif University Researchers Supporting Project number (TURSP-2020/28), Taif University, Taif, Saudi Arabia.

Conflicts of Interest: The authors declare no conflict of interest.

\section{References}

1. Barzinjy, A.A.; Hamad, S.M.; Aydın, S.; Ahmed, M.H.; Hussain, F.H.S. Green and eco-friendly synthesis of Nickel oxide nanoparticles and its photocatalytic activity for methyl orange degradation. J. Mater. Sci. Mater. Electron. 2020, 31, 11303-11316. [CrossRef]

2. Br, S.; Xr, J. Effect of calcination time on structural, optical and antimicrobial properties of nickel oxide nanoparticles. Theor. Comput. Sci. 2016, 3, 149-159. [CrossRef]

3. El-Kemary, M.; Nagy, N.; El-Mehasseb, I. Nickel oxide nanoparticles: Synthesis and spectral studies of interactions with glucose. Mater. Sci. Semicond. Process. 2013, 16, 1747-1752. [CrossRef]

4. Suresh, K.C.; Balamurugan, A. Evaluation of structural, optical, and morphological properties of nickel oxide nanoparticles for multi-functional applications. Inorg. Nano-Metal. Chem. 2020, 51, 296-301. [CrossRef]

5. Lingaraju, K.; Raja Naika, H.; Nagabhushana, H.; Jayanna, K.; Devaraja, S.; Nagaraju, G. Biosynthesis of nickel oxide nanoparticles from euphorbia heterophylla (L.) and their biological application. Arab. J. Chem. 2020, 13, 4712-4719. [CrossRef]

6. Ezhilarasi, A.A.; Vijaya, J.J.; Kaviyarasu, K.; Zhang, X.; Kennedy, L.J. Green synthesis of nickel oxide nanoparticles using solanum trilobatum extract for cytotoxicity, antibacterial and photocatalytic studies. Surf. Interfaces 2020, 20, 100553. [CrossRef]

7. Feiona, T.A.; Sabeena, G.; Bagavathy, M.S.; Pushpalaksmi, E.; Samraj, J.J. Recent advances in the synthesis and characterization of nanoparticles: A green adeptness for photocatalytic and antibacterial activity. Nat. Environ. Pollut. Technol. 2021, 20,657-663. [CrossRef]

8. Mokoena, T.P.; Swart, H.C.; Motaung, D.E. A review on recent progress of p-type nickel oxide based gas sensors: Future perspectives. J. Alloys Compd. 2019, 805, 267-294. [CrossRef]

9. Arora, A.K.; Jaswal, V.S.; Singh, K.; Singh, R. Applications of metal/mixed metal oxides as photocatalyst: A review. Orient. J. Chem. 2016, 32, 2035-2042. [CrossRef]

10. Niklasson, G.A.; Granqvist, C.G. Electrochromics for smart windows: Thin films of tungsten oxide and nickel oxide, and devices based on these. J. Mater. Chem. 2007, 17, 127-156. [CrossRef]

11. Danjumma, S.G.; Abubakar, Y.; Suleiman, S. Nickel Oxide (NiO) devices and applications: A review. Int. J. Eng. Res. Technol. 2019, $V 8,461-467$. [CrossRef]

12. Hameed, A.; Gombac, V.; Montini, T.; Graziani, M.; Fornasiero, P. Synthesis, Characterization and photocatalytic activity of $\mathrm{NiO}-\mathrm{Bi}_{2} \mathrm{O}_{3}$ nanocomposites. Chem. Phys. Lett. 2009, 472, 212-216. [CrossRef] 
13. Haq, S.; Dildar, S.; Ali, M.B.; Mezni, A.; Hedfi, A.; Shahzad, M.I.; Shahzad, N.; Shah, A. Antimicrobial and antioxidant properties of biosynthesized of $\mathrm{NiO}$ nanoparticles using raphanus sativus (R. sativus) extract. Mater. Res. Express 2021, 8, 055006. [CrossRef]

14. Sone, B.T.; Fuku, X.G.; Maaza, M. Physical \& electrochemical properties of green synthesized bunsenite NiO nanoparticles via callistemon viminalis' extracts. Int. J. Electrochem. Sci. 2016, 11, 8204-8220. [CrossRef]

15. Angel Ezhilarasi, A.; Judith Vijaya, J.; Kaviyarasu, K.; John Kennedy, L.; Ramalingam, R.J.; Al-Lohedan, H.A. Green synthesis of $\mathrm{NiO}$ nanoparticles using aegle marmelos leaf extract for the evaluation of in-vitro cytotoxicity, antibacterial and photocatalytic properties. J. Photochem. Photobiol. B Biol. 2018, 180, 39-50. [CrossRef]

16. Anand, G.T.; Nithiyavathi, R.; Ramesh, R.; John Sundaram, S.; Kaviyarasu, K. Structural and optical properties of nickel oxide nanoparticles: Investigation of antimicrobial applications. Surf. Interfaces 2020, 18, 100460. [CrossRef]

17. Sinha, S.; Murugesan, T.; Maiti, K.; Gayen, J.R.; Pal, M.; Saha, B.P. Evaluation of anti-inflammatory potential of bergenia ciliata sternb. rhizome extract in rats. J. Pharm. Pharmacol. 2010, 53, 193-196. [CrossRef]

18. Hamid, A.; Haq, S.; Ur Rehman, S.; Akhter, K.; Rehman, W.; Waseem, M.; Ud Din, S.U.; Zain-ul-Abdin; Hafeez, M.; Khan, A.; et al. Calcination temperature-driven antibacterial and antioxidant activities of fumaria indica mediated copper oxide nanoparticles: Characterization. Chem. Pap. 2021, 75, 4189-4198. [CrossRef]

19. Sagadevan, S.; Podder, J. Investigations on structural, optical, morphological and electrical properties of nickel oxide nanoparticles. Int. J. Nanoparticles 2015, 8, 289-301. [CrossRef]

20. Goel, R.; Jha, R.; Ravikant, C. Investigating the structural, electrochemical, and optical properties of p-type spherical nickel oxide (NiO) nanoparticles. J. Phys. Chem. Solids 2020, 144, 109488. [CrossRef]

21. Shah, A.; Haq, S.; Rehman, W.; Muhammad, W.; Shoukat, S.; Rehman, M. Photocatalytic and antibacterial activities of paeonia emodi mediated silver oxide nanoparticles. Mater. Res. Express 2019, 6, 045045. [CrossRef]

22. Ahmad, S.; Fahmina, B.; Aftab, Z.; Mondal, H.; Kareem, A.; Ullah, A. Photocatalytic degradation of carcinogenic congo red dye in aqueous solution, antioxidant activity and bactericidal effect of $\mathrm{NiO}$ nanoparticles. J. Iran. Chem. Soc. 2020, 17, 215-227. [CrossRef]

23. Shoukat, S.; Rehman, W.; Haq, S.; Waseem, M.; Shah, A. Synthesis and characterization of zinc stannate nanostructures for the adsorption of chromium (VI) ions and photo-degradation of rhodamine 6G. Mater. Res. Express 2019, 6, 115052. [CrossRef]

24. Haq, S.; Rehman, W.; Waseem, M.; Meynen, V.; Awan, S.U.; Khan, A.R.; Hussain, S.; Zain-ul-Abdin; Din, S.U.; Hafeez, M.; et al. Effect of annealing temperature on structural phase transformations and band gap reduction for photocatalytic activity of mesopores $\mathrm{TiO}_{2}$ nanocatalysts. J. Inorg. Organomet. Polym. Mater. 2021, 31, 1312-1322. [CrossRef]

25. Haq, S.; Yasin, K.A.; Rehman, W.; Waseem, M.; Ahmed, M.N.; Shahzad, M.I.; Shahzad, N.; Shah, A.; Rehman, M.U.; Khan, B. Green synthesis of silver oxide nanostructures and investigation of their synergistic effect with moxifloxacin against selected microorganisms. J. Inorg. Organomet. Polym. Mater. 2020, 31, 1134-1142. [CrossRef]

26. Haq, S.; Ahmad, P.; Khandaker, M.U.; Faruque, M.R.I.; Rehman, W.; Waseem, M.; Din, S.U. Antibacterial, antioxidant and physicochemical investigations of tin dioxide nanoparticles synthesized via microemulsion method. Mater. Res. Express 2021, 8, 035013. [CrossRef]

27. Shah, A.; Tauseef, I.; Ali, M.B.; Yameen, M.A.; Mezni, A.; Hedfi, A.; Haleem, S.K.; Haq, S. In-vitro and in-vivo tolerance and therapeutic investigations of phyto-fabricated iron oxide nanoparticles against selected pathogens. Toxics 2021, 9, 105. [CrossRef] [PubMed]

28. Sirelkhatim, A.; Mahmud, S.; Seeni, A.; Kaus, N.H.M.; Ann, L.C.; Bakhori, S.K.M.; Hasan, H.; Mohamad, D. Review on zinc oxide nanoparticles: Antibacterial activity and toxicity mechanism. Nano-Micro Lett. 2015, 7, 219-242. [CrossRef]

29. Haq, S.; Abbasi, F.; Ben Ali, M.; Hedfi, A.; Mezni, A.; Rehman, W.; Waseem, M.; Khan, A.R.; Shaheen, H. Green synthesis of cobalt oxide nanoparticles and the effect of annealing temperature on their physiochemical and biological properties. Mater. Res. Express 2021, 8, 075009. [CrossRef] 